\title{
Identifying the Risk Factors for the Failure of the Tension-Free Vaginal Tape
}

\author{
Ceyhun Cenk (D), Aysu Akça (D), Nadiye Dugan (1), Berna Arslan Çetin (1) \\ Department of Gynecology and Obstetrics, University of Health Sciences İstanbul Kanuni Sultan Süleyman Training and Research Hospital, İstanbul, Turkey \\ Cite this article as: Ceyhun C, Akça A, Dugan N, Aslan Çetin B. Identifying the Risk Factors for the Failure of the Tension-Free Vaginal Tape. \\ JAREM 2018; 8(3): 129-32.
}

\begin{abstract}
Objective: To determine the risk factors leading to failure of the tension-free vaginal tape (TVT), which is an efficient procedure for the surgical treatment of stress incontinence and stress-predominant mixed incontinence.

Methods: This study included 195 patients who underwent TVT surgery for the treatment of stress incontinence and mixed urinary incontinence at our hospital between 2012 and 2016 and who were not lost to follow-up. In the postoperative period, the two groups of patients, those with or without improved incontinence symptoms upon straining in the upright position, were compared in terms of age, parity, body mass index (BMI), menopausal status, types of urinary incontinence, Valsalva leak point pressure (VLPP), and the elapsed time after surgery.

Results: Of the 195 patients who had incontinence upon straining in the upright position preoperatively, $24.6 \%$ continued to experience urinary leaks in the postoperative period. After TVT application, no significant differences were found between the continent and incontinent patient groups in terms of age, BMI, follow-up duration, and menopausal status, whereas mixed urinary incontinence and low VLPP values (VLPP $\leq 60 \mathrm{~cm}$ $\mathrm{H}_{2} \mathrm{O}$ ) were determined as independent risk factors for failure after TVT application $(\mathrm{p}<0.05)$.

Conclusion: The presence of intrinsic sphincter deficiency $\left(\mathrm{VLPP} \leq 60 \mathrm{~cm} \mathrm{H}_{2} \mathrm{O}\right)$ and mixed urinary incontinence are significant risk factors leading to failure of TVT surgery in the postoperative period.

Keywords: Risk factors, failure, urinary incontinence, tension-free vaginal tape
\end{abstract}

ORCID IDs of the authors: C.C. 0000-0003-3387-185X; A.A. 0000-0002-8644-7908; ; N.D. 0000-0001-8337-3432; B.A.Ç. 0000-0001-6856-1822.

\section{INTRODUCTION}

Urinary incontinence $(\mathrm{UI})$ is an important health problem affecting millions of women worldwide. It is described by the International Continence Society as "involuntary urine leakage, which causes social and hygienic problems" (1). It affects $8.5 \%$ of the women aged $15-64$ years and $11.6 \%$ over 65 years (2). Conservative methods (lifestyle changes, pelvic floor muscle training, bladder training, and pharmacotherapy) are accepted as the first-line therapy for all incontinence types. Surgery should be applied to patients who do not respond to the initial treatment (3).

Tension-free vaginal tape (TVT) was first described in 1996 in the surgical treatment of stress urinary incontinence (SUI) (4). This method, which has a high success rate and is a minimally invasive method, has become the gold standard in the surgical treatment of SUI and has been used in the treatment of mixed urinary incontinence (MUI) with no response to conservative treatment $(5,6)$. There are many comparative studies on the long-term and short-term outcomes and TVT complication rates in the literature, but there are few studies aimed at predicting the TVT success.
In this study, our primary aim was to determine the risk factors leading to treatment failure in patients who had undergone a TVT operation due to UI. Our secondary aim is to reveal subjective success rates after TVT.

\section{METHODS}

A total of 195 patients who underwent a TVT operation due to SUI and MUI in our hospital between 2012 and 2016, and who were still followed up after the postoperative period, were included in our study. The presence of psychiatric and neurological disorders, previous radical pelvic surgery, and time lapsed after surgery $<5$ months were accepted as exclusion criteria. Verbal consent was obtained from all patients.

Data, including age, parity, body mass index (BMI), the menopausal status, incontinence type, the stage of pelvic organ prolapse, valsalva leak point pressure (VLPP), time after surgery, presence of preoperative urine incontinence with straining while standing and in the lithotomy position in the study group, were obtained from the records. The patients were questioned about the presence of $\mathrm{UI}$ when standing and in the lithotomy position by straining postoperatively. The presence of urine leakage while 
standing with straining postoperatively was accepted as unsuccessful.

This study was conducted in accordance with the principles of the Declaration of Helsinki, "Ethical Principles for Medical Research Involving Human Subjects" (amended in October 2013).

\section{Statistical Analysis}

Data were analyzed using the Statistical Package for the Social Sciences version 16.0 program (SPSS Inc., Chicago, Illinois, USA). Continuous data were written as the mean \pm standard deviation (SD) and analyzed by the Wilcoxon signed rank test for statistical significance. Categorical data were expressed as numerical values and percentages. They were compared with the McNemar chi-squared test, and a p-value $<0.05$ was accepted as statistically significant. Patients were divided into two groups, as the patients who were considered to be unsuccessful after TVT and the others, and they were compared with univariate analysis in terms of demographics and clinical characteristics. The covariants with $p<0.15$ were introduced into the multivariate logistic regression model to find independent risk factors related to failure.

\section{RESULTS}

The mean age of the patients was $51.1 \pm 9.5$ years, and 145 (74.4\%) cases were postmenopausal. While $62.1 \%$ of patients were operated for SUI, $50.8 \%$ had the stage I pelvic organ prolapse. The preoperative demographic and clinical features of the study group are summarized in Table 1.

The mean postoperative follow-up period was $19.4 \pm 9.8$ months. While the minimum follow-up period was 5 months, the maximum follow-up period was 40 months. In the postoperative period, UI continued in 48 (24.6\%) of 195 patients (100\%) who had preoperative $\mathrm{UI}$ with straining while standing. Again, in 148 (75.9\%) patients who had UI with straining in lithotomy preoperatively, urinary incontinence (UI) persisted or deteriorated in 37 (19\%) patients (Table 2). When these preoperative and postoperative parameters were compared statistically, a significant decrease was observed in all of them $(p<0.001)$ (Table 3$)$.

Accepting the presence of urine leakage while standing with straining postoperatively as unsuccessful, the demographical and clinical features of the unsuccessful cases were compared with the successful ones. No significant difference was found between the successful group and the unsuccessful group in terms of age, BMI, duration of the follow-up, and menopausal status, but there were more patients with $\mathrm{MUI}$ and the VLPP $\leq 60 \mathrm{cmH}_{2} \mathrm{O}$ in the unsuccessful group $(p<0.05)$ (Table 4$)$. When the factors with $p<0.15$ in the univariant analysis were introduced into the multivariate logistic regression model, MUI and VLPP $\leq 60 \mathrm{~cm} \mathrm{H}_{2} \mathrm{O}$ have not lost their significance. Table 5 shows the odds ratios, confidence intervals, and p-values of these factors.

Five patients had bladder perforation during operation, and 4 of them were noticed when intraoperative cystoscopy was performed, and the mesh was withdrawn and reinserted. In 1 patient, on the postoperative Day 1, it was detected by the presence of urine in the holes of TVT applicators, and the mesh was removed. Perforation areas were improved by keeping the urinary catheters of all patients for 15 days.
Table 1. Preoperative demographic and clinical features of the study group

\begin{tabular}{|l|c|c|}
\hline Demographic Features & Study Group $\mathbf{n = 1 9 5}$ & Min-Max \\
\hline Age $($ mean \pm SD) & $51.1 \pm 9.5$ & $32-79$ \\
\hline Parity $($ mean \pm SD) & $5.2 \pm 2.3$ & $2-13$ \\
\hline BMI (mean \pm SD) & $30 \pm 4.1$ & $18-47$ \\
\hline
\end{tabular}

Menopausal state, $\mathrm{n}(\%)$

\begin{tabular}{l|c|}
\hline premenopausal & $50(25.6)$ \\
\hline postmenopausal & $145(74.4)$ \\
\hline
\end{tabular}

VLPP, $\mathbf{n}(\%)$

\begin{tabular}{|l|c|c|}
\hline$\leq 60 \mathrm{cmH}_{2} \mathrm{O}$ & $37(19)$ \\
\hline $61-120 \mathrm{cmH}_{2} \mathrm{O}$ & $140(71.7)$ \\
\hline$>20 \mathrm{cmH}_{2} \mathrm{O}$ & $18(9.3)$ \\
\hline
\end{tabular}

\section{Type of incontinence, $\mathrm{n}(\%)$}

\begin{tabular}{|l|c|c|}
\hline Stress & $121(62.1)$ \\
\hline Mixed & $74(37.9)$ \\
\hline
\end{tabular}

Stage of POP-Q, n (\%)

\begin{tabular}{|c|c|}
\hline 0 & $3(1.5)$ \\
\hline 1 & $99(50.8)$ \\
\hline 2 & $46(23.6)$ \\
\hline 3 & $41(21)$ \\
\hline 4 & $4(3.1)$ \\
\hline
\end{tabular}

SD: standard deviation; Max: maximum; Min: minimum; BMI: body mass index; VLPP: valsalva leak point pressure; POP-Q: pelvic organ prolapse quantification

Table 2. Subjective measurement parameters of the patients related to the urinary incontinence and follow-up periods

\begin{tabular}{|c|c|c|}
\hline & $\begin{array}{l}\text { Study Group } \\
\quad(n=195)\end{array}$ & Max-Min \\
\hline \multicolumn{3}{|c|}{ Preoperative urinary incontinence } \\
\hline Standing n (\%) & $170(87.2)$ & \\
\hline Lithotomy n (\%) & $148(75.9)$ & \\
\hline \multicolumn{3}{|c|}{ Postoperative urinary incontinence } \\
\hline Standing $n(\%)$ & $48(24.6)$ & \\
\hline Lithotomy n (\%) & $37(19)$ & \\
\hline Follow-up period (mean \pm SD) & $19.4 \pm 9.8$ & $40-5$ \\
\hline
\end{tabular}

One of these patients who developed severe infection was hospitalized and was treated with a broad-spectrum antibiotic for 15 days. In 8 patients, hematoma developed in the area where the TVT applicator passed. Two of these patients had hematomas greater than $8 \mathrm{~cm}$ and were symptomatic. One of them was drained vagi- 
Table 3. Comparison of preoperative and postoperative lithotomy and standing urinary incontinence rates

\begin{tabular}{|l|c|c|c|}
\hline & Preop. & Postop. & p \\
\hline $\begin{array}{l}\text { Urinary incontinence } \\
\text { (standing), n \% }\end{array}$ & $170(87.2)$ & $48(24.6)$ & $<0.001$ \\
\hline $\begin{array}{l}\text { Urinary incontinence } \\
\text { (lithotomy), n \% }\end{array}$ & $148(75.9)$ & $37(19)$ & $<0.001$ \\
\hline \begin{tabular}{l} 
Preop: preoperative; Postop: postoperative \\
\hline
\end{tabular}
\end{tabular}

Table 4. Comparison of urinary continent (successful) and incontinent (unsuccessful) groups in the standing position after TVT

\begin{tabular}{|c|c|c|c|}
\hline & $\begin{array}{c}\text { Successful } \\
n=147\end{array}$ & $\begin{array}{c}\text { Unsuccessful } \\
n=48\end{array}$ & $p$ \\
\hline Age & $51.7 \pm 1.8$ & $50.8 \pm 0.7$ & 0.1 \\
\hline BMI & $29.9 \pm 0.8$ & $30.5 \pm 0.3$ & 0.4 \\
\hline Follow-up period & $22.4 \pm 1.3$ & $18.6 \pm 0.7$ & 0.07 \\
\hline \multicolumn{4}{|l|}{ Menopause, n (\%) } \\
\hline No & $37(25.1)$ & $13(27.0)$ & \multirow[t]{2}{*}{0.79} \\
\hline Yes & $110(74.8)$ & $35(72.9)$ & \\
\hline \multicolumn{4}{|l|}{ VLPP, n (\%) } \\
\hline$\leq 60 \mathrm{cmH}_{2} \mathrm{O}$ & $19(13)$ & $23(47.9)$ & \multirow[t]{2}{*}{$<0.01$} \\
\hline$>60 \mathrm{cmH}_{2} \mathrm{O}$ & $128(87)$ & $25(52)$ & \\
\hline \multicolumn{4}{|c|}{ Type of incontinence, n (\%) } \\
\hline Stress & $108(73.5)$ & $3(6.1)$ & \multirow[t]{2}{*}{$<0.01$} \\
\hline Mixed & $39(26.5)$ & 45 (93.9) & \\
\hline
\end{tabular}

Table 5. Multivariate analysis of risk factors affecting failure after TVT

\begin{tabular}{|l|c|c|c|}
\hline & OR & $95 \% \mathbf{C l}$ & $\mathbf{P}$ \\
\hline Type of incontinence & 97.3 & $17.4-542$ & 0.01 \\
\hline VLPP $\leq 60 \mathrm{cmH}_{2} \mathrm{O}$ & 7.69 & $2.32-25$ & $<0.01$ \\
\hline OR: odds ratio; $\mathrm{Cl}$ : confidence interval; VLPP: valsalva leak point pressure
\end{tabular}

nally and the other was discharged by laparotomy by entering into the space of Retzius. Other hematoma cases were given antibiotics and called for weekly controls, and hematomas were found to be resolved spontaneously. In the postoperative period, urinary retention occurred in 6 patients. These patients were applied urinary catheter and anti-inflammatory treatment for 7 to 21 days, and the mesh of 3 patients was cut because of persisting residues.

\section{DISCUSSION}

Considering the literature on the TVT failure, quite different percentages have been reported (between 16\% and 30\%) (6). The reason for this is the differences in patients included in the study, cure definition, evaluation systems, and follow-up periods. In our study, the rate of failure was $24.6 \%$, and this high value may be related to the fact that the patient group is not just isolated SUI but that it also included patients with $\mathrm{MCl}$. Likewise, studies with isolated SUI patients showed a higher success rate than patients with MUI (7). In accordance with the literature, we also found that the MUI type had a negative effect on the TVT success.

Our definition of failure is the presence of urine leakage while standing with straining in the postoperative period. This is an easy-to-evaluate and effective criterion. In the standing position, the mobility of the urethra and the angle it makes with the bladder decreases so that UI becomes easier (8). Therefore, standing $\mathrm{UI}$ as a criterion of failure was preferred to lithotomy.

Aging and menopause cause structural and functional changes in the lower urinary tract. There are different results in the literature about the TVT failure in older women. While one group of researchers argued that aging leads to an increased TVT failure, another says it is not the case (9-12). In our study, we found that the age and menopause status had no effect on the TVT success.

In patients followed for 10 years, Aigmueller et al. (13) determined that a BMI over 30 was the only independent risk factor for the objective and subjective failure. Again, there is no clear consensus in this area when the research was made. Although most studies indicate that BMI increases failure, there are studies showing that it does not affect the failure $(14,15)$. In our cohort, there was no significant difference in terms of BMI between successful and unsuccessful groups after TVT $(p=0.4)$.

Studies based on a long follow-up time ( $\geq 5$ years) showed that the efficacy of the procedure was not reduced by the time $(5,7)$. Our study does not have a long-term follow-up period, the shortest being 5 months and the longest 40 months, and this does not affect the success statistically.

In urodynamic tests, a VLPP $\leq 60 \mathrm{cmH}_{2} \mathrm{O}$ is interpreted in favor of the intrinsic sphincter deficiency. There are also controversial results in the literature that try to predict success with preoperative VLPP values. Cetinel et al. found no relation between preoperative VLPP values and cure rates (16). However, most studies in the literature state that low VLPP values may be predictive of the postoperative failure $(6,7,17)$. In line with most studies, we found that a VLPP $\leq 60 \mathrm{cmH}_{2} \mathrm{O}$ in the preoperative urodynamics was a risk factor for failure.

\section{CONCLUSION}

In this analysis, age, the menopausal status, BMI, and the followup period did not affect the failure after TVT, but a VLPP $\leq 60 \mathrm{~cm}$ $\mathrm{H}_{2} \mathrm{O}$ and the mixed type of incontinence were independent risk factors that increased the failure.

Although more randomized controlled trials are needed to make a definite conclusion on this issue, patients should be informed that the presence of intrinsic sphincter deficiency (VLPP $\leq 60 \mathrm{~cm}$ $\mathrm{H}_{2} \mathrm{O}$ ) or mixed incontinence accompanied by urgency findings in the TVT-planned patients would decrease postoperative success rates. 
Ethics Committee Approval: All procedures performed were in accordance with World Medical Association Declaration of Helsinki "Ethical Principles for Medical Research Involving Human Subjects", (amended in October 2013)

Informed Consent: Verbal informed consent was obtained from patients who participated in this study.

Peer-review: Externally peer-reviewed.

Author Contributions: Concept - A.A., C.C., N.D., B.A.Ç.; Design - A.A., C.C., N.D., B.A.Ç.; Supervision - A.A., C.C., N.D., B.A.Ç.; Resources A.A.,N.D.; Materials - A.A; Data Collection and/or Processing - C.C.,B.A.Ç; Analysis and/or Interpretation - A.A.; Literature Search - A.A.,B.A.Ç.; Writing Manuscript - A.A., C.C.; Critical Review - A.A., N.D

Acknowledgements: The authors are grateful to Alev Atış Aydın for providing helpful suggestions.

Conflict of Interest: The authors have no conflict of interest to declare.

Financial Disclosure: The authors declared that this study has received no financial support.

\section{REFERENCES}

1. Abrams P, Cardozo L, Fall M, Griffiths D, Rosier P, Ulmsten U, et al. Sub-committee of the International Continence Society. The standardisation of terminology of lower urinary tract function: report from the Standardisation Sub-committee of the International Continence Society. Neurourol Urodyn 2002; 21: 167-78. [CrossRef]

2. Thomas TM, Plymat KR, Blannin J, Meade TW. Prevalence of urinary incontinence. Br Med J 1980; 281: 1243-5. [CrossRef]

3. Gomelsky A, Dmochowski R. Treatment of mixed urinary incontinence in women. Curr Opin Obstet Gynecol 2011; 23: 371-5. [CrossRef]

4. Ulmsten $U$, Henriksson L, Johnson P, Varhos $G$. An ambulatory surgical procedure under local anesthesia for treatment of female urinary incontinence. Int Urogynecol J Pelvic Floor Dysfunct 1996; 7: 81-5. [CrossRef]

5. Serati M, Salvatore S, Uccella S, Artibani W, Novara G, Cardozo L, et al. Surgical treatment for female stress urinary incontinence: what is the gold-standard procedure? Int Urogynecol J Pelvic Floor Dysfunct 2009; 20: 619-21. [CrossRef]
6. Paick JS, Ku JH, Kim SW, Oh SJ, Son H, Shin JW. Tension-free vaginal tape procedure for the treatment of mixed urinary incontinence: significance of maximal urethral closure pressure. J Urol 2004; 172: 1001-5. [CrossRef]

7. Handa VL, Jensen JK, Ostergard DR. The effect of patient position on proximal urethral mobility. Obstet Gynecol 1995; 86: 273-6. [CrossRef]

8. Lee KS, Choo MS, Doo CK, Han DH, Lee YS, Kim JY, et al. The Long Term (5-Years) Objective TVT Success Rate Does Not Depend on Predictive Factors at Multivariate Analysis. Eur Urol 2008; 53: 176-83. [CrossRef]

9. Moore RD, Miklos JR. Colpocleisis and tension-free vaginal tape sling for severe uterine and vaginal prolapse and stress urinary incontinence under local anesthesia. J Am Assoc Gynecol Laparosc 2003; 10: 276-80. [CrossRef]

10. Sevestre S, Ciofu C, Deval B, Traxer O, Amarenco G, Haab F. Results of the tension-free vaginal tape technique in the elderly. Eur Urol 2003; 44: 128-31. [CrossRef]

11. Walsh K, Generao SE, White MJ, Katz D, Stone AR. The influence of age on quality of life outcome in women following a tension-free vaginal tape procedure. J Urol 2004; 171: 1185-8. [CrossRef]

12. Nilsson CG, Kuuva N. The tension-free vaginal tape procedure is successful in the majority of women with indications for surgical treatment of urinary stress incontinence. BJOG 2001; 108: 414-9. [CrossRef]

13. Aigmueller T, Trutnovsky G, Tamussino K, Kargl J, Wittmann A, Surtov M, Kern P, Frudinger A, Riss P, Bjelic-Radisic V. Ten-year follow-up after the tension-free vaginal tape procedure. Am J Obstet Gynecol 2011; 205: 496. e1-5.

14. Hellberg D, Holmgren C, Lanner L, Nilsson S. The very obese woman and the very old woman: tension-free vaginal tape for the treatment of stress urinary incontinence. Int Urogynecol J Pelvic Floor Dysfunct 2007; 18: 423-9. [CrossRef]

15. Zivkovic F, Tamussino K, Pieber D, Haas J. Body mass index and outcome of incontinence surgery. Obstet Gynecol 1999; 93: 753-6. [CrossRef]

16. Cetinel B, Demirkesen O, Onal B, Akkus E, Alan C, Can G. Are there any factors predicting the cure and complication rates of tension-free vaginal tape? Int Urogynecol J Pelvic Floor Dysfunct 2004; 15: 188-93. [CrossRef]

17. Liapis A, Bakas P, Salamalekis E, Botsis D, Creatsas G. Tension-free vaginal tape (TVT) in women with low urethral closure pressure. Eur J Obstet Gynecol Reprod Biol 2004; 116: 67-70. [CrossRef] 